\title{
ZHOURI, Andréa (Org.). 2018. Mineração, violências e resistências: um campo aberto à produção de conbecimento no Brasil. Marabá, PA: Editorial iGuana; ABA. $711 \mathrm{~kb}$; e-PUB.
}

\author{
ISRAEL DE JESUS ROCHA
}

O que significa produzir conhecimento a partir das experiências acadêmicas em um campo minado como o da mineração no Brasil? Podemos iniciar este breve comentário sobre o livro Mineração, violências e resistências: um campo aberto à produção de conhecimento no Brasil, organizado por Andréa Zhouri, perguntando-nos como e em quais circunstâncias pesquisadores e sujeitos afetados direta e indiretamente pelos grandes projetos tensionam e são colocados em situações-limite que envolvem a exploração mineral em diversas regiões do país. Os capítulos organizados por Zhouri revelam, com detalhes de campo, temas sensíveis aos efeitos da mineração no Brasil e abrem espaço para a discussão sobre o intricado processo de violência das afetações que são colocados em prática a partir das dinâmicas definidas por mercados mundiais, mas que encontram sua materialidade nos territórios. Afirma Zhouri, no Brasil, a mineração figura em estudos pontuais e tangenciais à antropologia do desenvolvimento e é um campo ainda a ser explorado face ao aprofundamento do modelo econômico neoextrativista que coloca os países latino-americanos em posição de subordinação na economia global.

Já na introdução a autora nos mostra o quadro no qual os trabalhos antropológicos interessados nos desdobramentos dos megaprojetos de mineração. As dinâmicas que configuram as lutas por recursos na contemporaneidade apresentam um amplo espectro de retrocessos institucionais, sobretudo o desmonte dos sistemas de regulação ambiental e das normas que asseguram direitos territoriais dos povos indígenas e comunidades quilombolas. Os retrocessos são acompanhados, geralmente, por uma série de violências que caminham no mesmo ritmo dos processos de despolitização e criminalização dos atingidos. Então, a questão que se coloca para a Antropologia, em particular, e para a produção do conhecimento, no geral, é quais são os desafios que estão presentes no interior do campo minado que é a pesquisa que envolve a mineração no Brasil e na América Latina.

Neste cenário, o trabalho do antropólogo é frequentemente confrontado e sua posição enquanto cientista social é questionada. Por isso, para Zhouri, mais do que a observação participante, a presença e olhar situados do antropólogo estão permeados pelas condições de produção associadas aos efeitos do lugar. Estes lugares enunciativos são então marcados por constrangimentos e potencialidades próprios do papel do cientista situado no campo das pesquisas sociais sobre a mineração. Assim, neste campo 
minado a produção do conhecimento científico exige reflexividade e responsabilidade uma vez que pode gerar efeitos e interferências nos processos sociais.

Para mostrar como a Antropologia tem se deslocado e produzido conhecimento nesse campo o livro foi organizado em duas partes. A primeira procura dar conta do desastre do Rio Doce e os desdobramentos que envolvem as afetações, resistências e políticas. Subdivide-se em quatro capítulos que se debruçam sobre a gestão das afetações, o lugar das emoções nas manifestações e conflitos, a privatização da regulação mineral e uma genealogia política do desastre. A segunda parte do livro procura desenvolver a relação entre a produção de conhecimento, as violências e resistências ligadas aos contextos dos grandes projetos de mineração. Seus três capítulos procuram discutir as violências produzidas a partir da construção da legalidade da implantação do projeto Minas-Rio, o conflito ambiental em torno da mineração de urânio e fosfato no Ceará e os efeitos derrame atrelados à atividade de mineração de ferro no Pará e sua expansão para a Amazônia oriental brasileira.

No primeiro capítulo, Zhouri e autores procuram analisar os processos que envolvem as políticas de reparação e a gestão das afetações em torno do desastre do Rio Doce, com o rompimento da barragem de minério de ferro em Mariana. A partir do acompanhamento das reunióes entre as empresas e os atingidos, os autores passaram a analisar a forma como se constrói uma performance de ser atingido a partir de procedimentos, termos e instrumentos ordinários que são mobilizados em torno do licenciamento ambiental, agravando as vulnerabilidades desencadeadas pelo desastre e também marginalizando as linguagens e formas de mobilização dos atingidos. A gestão da crise a partir de uma série de formulários e dispositivos, dessa forma, passa a solapar as possibilidades de participação social dos atingidos, aprofundando o quadro de sofrimento e produzindo processos duradouros de crise social. De outro modo, o poder público e as empresas de mineração passam a deslocar a administração dos desastres da esfera criminal e sua judicialização para o eixo do tratamento gerencial dos conflitos ambientais. Este deslocamento acaba expondo tecnologias e dispositivos orientados para a construção de pretensos pactos. No caso de Mariana, o gerenciamento da crise mobilizou mesas de negociação e assinaturas de termos de ajustamento de conduta (TAC). Os autores então argumentam que esses dispositivos se realizam enquanto processos de contratualização e em detrimento dos espaços e possibilidades de participação dos atingidos.

É importante salientar que os conflitos ambientais são caracterizados pela irrupção de embates entre práticas distintas sobre o mesmo território, levando ao choque de práticas e formas de uso e controle dos recursos. Os conflitos ambientais surgem, assim, de distintas formas de apropriação técnica, econômica, social e cultural do mundo material. Os dispositivos utilizados para produzir simetria, em contextos de conflitos ambientais, como é o caso de Mariana, acabam revelando as posições assimétricas ocupadas pelos atingidos e agentes corporativos, enfraquecendo os direitos daqueles que passaram a sofrer com o desastre sociotécnico, produzido por uma série de decisões que envolvem humanos e não humanos.

Neste processo de produção do ser atingido a partir de dispositivos sociotécnicos articulados pelo desastre, as estruturas e terminologias do universo estatal e corporativo se tornam instrumentos de intervenção e gestão capazes de modular as formas de imaginação e construção das identidades e sen- 
tidos de pertença ao território. Os estragos causados pelo desastre remetem, dessa maneira, à produção do sofrimento social a partir de aspectos socioculturais e políticos que geram frustações, insegurança e incerteza em relação à definição de atingido e ao reconhecimento de seus direitos. Dessa forma, concluem os autores, os instrumentos previstos para o levantamento de dados não dimensionam os mecanismos capazes de captar o processo de reconstrução, como as redes sociais territorializadas, formas de uso e significação do espaço e dos recursos, valores culturais e outros desenvolvidos por décadas de experiência vivida nos territórios.

No capítulo dois, Losekann está interessada em compreender o papel das emoções na mobilização dos afetados, considerando aqueles que não foram imediatamente atingidos, mas que estavam vivendo as expectativas da chegada da lama que corria pelo Rio Doce nos municípios do Estado do Espírito Santo. Seu trabalho se concentra em entender como a interferência na vida dos sujeitos afetados provocou mobilização e ação coletiva contestadora. Losekann então procura demonstrar como as dinâmicas emocionais envolvem a organização dos afetados e a construção do enquadramento de injustiça. Este processo considera a mobilização social enquanto ação coletiva através da qual pessoas apresentam reivindicações contestatórias de forma coordenada e rotineira. Assim, o que importa para que o desastre seja um fator de mobilização é a forma como os sujeitos o vivenciam, as dimensões da experiência e das interações e como estas se desdobram em emoções.

Para Losekann, os sujeitos vivenciaram o desastre do Rio Doce como experiência singular de tal forma que passaram a canalizar a experiência para a esfera da ação coletiva. A transformação do desastre nessa experiência singular acontece na medida em que provoca afetos particulares que dinamizam a ação dos sujeitos. A ênfase de Losekann na experiência singular e seu desdobramento emocional para a ação coletiva produz o enquadramento de injustiça e a busca por suas origens. Neste sentido, quanto mais concreto for o alvo, mais sólido é o enquadramento produzido para a justificação. Neste processo, o papel das emoções é central na conversão dos sentimentos individuais e autodirecionados para sentimentos compartilhados coletivamente.

No capítulo três, Santos e Milanez procuram analisar os traços de privatização da regulação mineral considerando o caso da Vale do Rio Doce. O argumento central dos autores reside na noção de regulação capturada, em que o controle de fato do Estado e suas agências regulatórias são anulados a partir da capacidade desenvolvida pelas corporações em neutralizar ou diminuir a efetividade dos entes reguladores. Para os autores, o controle ambiental no Brasil surgiu baseado em um padrão de regulação fraca, permanecendo aquém do esperado tanto em nível federal como em nível estadual. Este processo se deu a partir de um movimento de privatização e modificações nas formas de gestão, reduzindo o exercício de formas públicas em favor de formas privadas ou hibridas.

As consequências desse processo de privatização podem ser vistas através dos estudos de impacto ambiental, os quais têm se revelado insuficientes para caracterizar os potenciais impactos dos grandes projetos de mineração. Esta análise decorre da observação dos estudos que são realizados por consultorias contratadas pelas próprias mineradoras, produzindo situações claras de conflito de interesses. Para os autores, este processo acaba criando um elemento ainda mais perverso porque tende a minimizar 
as deficiências, desinformações e descumprimentos ambientais presentes nas fases de licenciamento a partir do subterfúgio das condicionantes, atenuando e flexibilizando a implementação dos projetos.

No capítulo quatro, Henri Acselrad revela uma preocupação assentada em três elementos. A ideia de uma irresponsabilidade organizada de classe, para destacar a forma como as escolhas de implementação de equipamentos perigosos e portadores de risco não são alheias ao perfil sociodemográfico das populações mais afetadas. Os movimentos por justiça ambiental têm chamado atenção para a forma como os danos associados aos projetos de desenvolvimento estão destinados a grupos étnicos e de baixa renda e que, enquanto não ocorrerem mudanças nos padrões de escolhas técnicas, nada mudará a situação dos afetados diretos pelos riscos dos empreendimentos. O segundo aspecto levantado pelo autor é a desconsideração dos alertas emitidos por cidadãos e grupos comprometidos com os interesses públicos. A partir da noção de lançador de alerta, usada pela sociologia pragmática do risco, Acselrad chama atenção para a dificuldade de escuta pública das advertências já que, no caso brasileiro, são limitadas as possibilidades de se levar em conta os interesses públicos na moderação da ânsia dos interesses privados. $\mathrm{O}$ último elemento considerado pelo autor diz respeito às restrições ao exercício da liberdade acadêmica quando se trata dos estudos de impacto ambiental. Para Acselrad, são muitos os casos em que a liberdade dos pesquisadores é cerceada quando estudam os impactos dos projetos de desenvolvimento sobre as práticas e condições de grupos subalternos. O cerceamento em muitos casos surge a partir de processos judiciais, questionamentos dos resultados das pesquisas, acusando os pesquisadores por conduta ideológica de suas pesquisas.

$\mathrm{Na}$ segunda parte do livro, Zhouri procura apresentar pesquisas que articulam os processos de violência associados à implantação dos grandes projetos e a produção do conhecimento de atores que passam a estar implicados com as consequências de tais empreendimentos. $O$ capítulo cinco vai se debruçar, neste sentido, sobre a forma como alguns aspectos do licenciamento do Projeto Minas-Rio provocaram, sob uma presumida legalidade, um violento processo de degradação ambiental e expropriação territorial de dezenas de comunidades rurais. Os autores chamam atenção para os efeitos derrame das transformações provocadas pelos empreendimentos de mineração que acabam por debilitar os direitos ou tolerar sua violação, mudando as formas de compreensão dos parâmetros de qualidade de vida, justiça e democracia. Assim, os processos de alegalidade dominaram a forma de condução de maneira a instrumentalizar brechas e interpretações da legislação com o intuito de alcançar certos interesses. No licenciamento do projeto Minas-Rio, as alegalidades funcionaram como um mecanismo de diluição de uma gama de danos ambientais que, uma vez nos holofotes, poderiam inviabilizar a concessão das licenças ambientais.

De forma ainda mais radical, o capítulo seis apresenta os processos que envolvem as fases de pesquisa e desenvolvimento do licenciamento ambiental para implantação de uma mina de urânio no Ceará. O artigo se concentra no trabalho desenvolvido pelo Grupo Tramas nos territórios programados para a construção do projeto de mineração de urânio e fosfato. A ênfase passa a ser dada à forma como os atores acionam conhecimentos de diversas ordens - nativo ou especializado - para desenvolver estratégias de disputa simbólica em torno do significado e das implicações do empreendimento nos territórios, em um contexto de conflito ambiental. Assim, face às estratégias dos técnicos 
associados à mina, passou-se a consolidar um conjunto de ações em torno dos movimentos sociais, moradores e pesquisadores no sentido de questionar as proposições que enfatizavam os aspectos positivos da implantação da mina. Este processo se deu de forma desigual, já que o consórcio responsável pelo empreendimento contava com um amplo corpo técnico. No esforço de combater as assimetrias na produção de conhecimento sobre as consequências da exploração do urânio na região, os grupos locais desenvolveram estratégias de articulação e trocas de experiência com cidades que já possuem minas de urânio no Brasil, produzindo materiais de comunicação que alertam sobre as consequências para o ambiente e a saúde daqueles que podem ser afetados direta e indiretamente.

O último capítulo do livro procura dar conta dos efeitos derrame das instalações de mineração de ferro no Pará. Os autores concluem que as experiências de resistência chamam atenção para os efeitos do processo de expansão dos empreendimentos sobre os territórios e os modos de vida a eles associados. Além da análise desses efeitos, salientam a necessária compreensão da relação entre Estado e empresas, sobretudo nos processos de financiamento público e concessões de exploração de terras que passam a ser direcionadas para a iniciativa privada. Na contramão deste processo desenvolvimentista, as comunidades têm se articulado a partir de redes de mobilização e emergência de novos sujeitos no espaço da ação coletiva para denunciar os processos associados à expansão da mineração na região norte.

Por fim, cabe salientar um aspecto comum entre os capítulos do livro. A experiência de campo é um dos elementos centrais na forma como os estudos aqui apresentados exploram a dimensão da pesquisa social enquanto elemento também definidor de questões relevantes. Este processo é enfatizado através da responsabilidade implicada na presença dos pesquisadores em campo e as consequências de seus relatos sobre o engajamento dos envolvidos. O que Zhouri reafirma quando enfatiza o papel questionador desses pesquisadores sobre a produção da ciência na conformação de discursos de verdade sobre os impactos dos grandes empreendimentos. Cabe então reafirmar a necessária leitura do livro como uma forma de compreensão do trabalho antropológico em um campo minado como é o setor da mineração no Brasil e os caminhos que o livro enseja para novas pesquisas na área da antropologia dos desastres e também nas discussões sobre antropologia da ciência e da tecnologia.

\section{Israel de Jesus Rocha é mestre e doutor em Ciências Sociais pela Universidade Federal da Babia (UFBA) e professor de Relaçóes Públicas na Universidade Federal do Amazonas (UFAM).}

SUBMETIDO: $21 / 11 / 2019$

APROVADO: $17 / 02 / 2020$ 